\title{
Ümit Özgür DEMİRCI, Eski Uygurca Fo ding xin da tuo luo ni, İstanbul: Kesit Yayınları, 2021. $300 \mathrm{~s}$.
}

[Kitap Tanıtım ve Değerlendirme/Book Review]

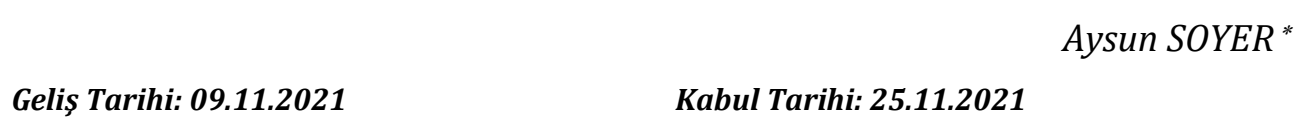

Çinliler tarafından Fo ding xin da tuo luo ni ve Fo ding xin da tuo luo ni jing biçimleriyle adlandırılan eser apokrif sūtra olarak nitelendirilen türdedir Hindistan'da ve Hint Yarımadası'nın batı bölgelerinde Sanskritçe olarak kaleme alınan sūtralar gerçek sūtra olarak adlandırılırken Çinlilerin kendi ürettikleri sūtralar ise “伪经” (apokrif uydurma-sūtra) olarak adlandırılmaktadır. Çinceden Eski Uygurcaya tercüme edilen uydurma sūtralardan olan Fo ding xin da tou lou ni, "Buddha-Usnisa'nın büyük Dharanisūtrasının özü", "Hastalıkları iyileştirmek ile doğuma yardım için Buddha-Usnisa metodunun özü" ve tehlikelerden koruma konusunda Tanrısal başarılara dair BuddhaUśnisa sūtralarının özü" olmak üzere üç bölümden oluşmaktadır. XIX. ve XX. yüzyılda Doğu Türkistan çevresine yapılan keşif gezilerinde Dunhuang mağaralarında bir metnin parçaları olarak ele geçirilen eserin belgeleri Berlin Bilimler Akademisinde

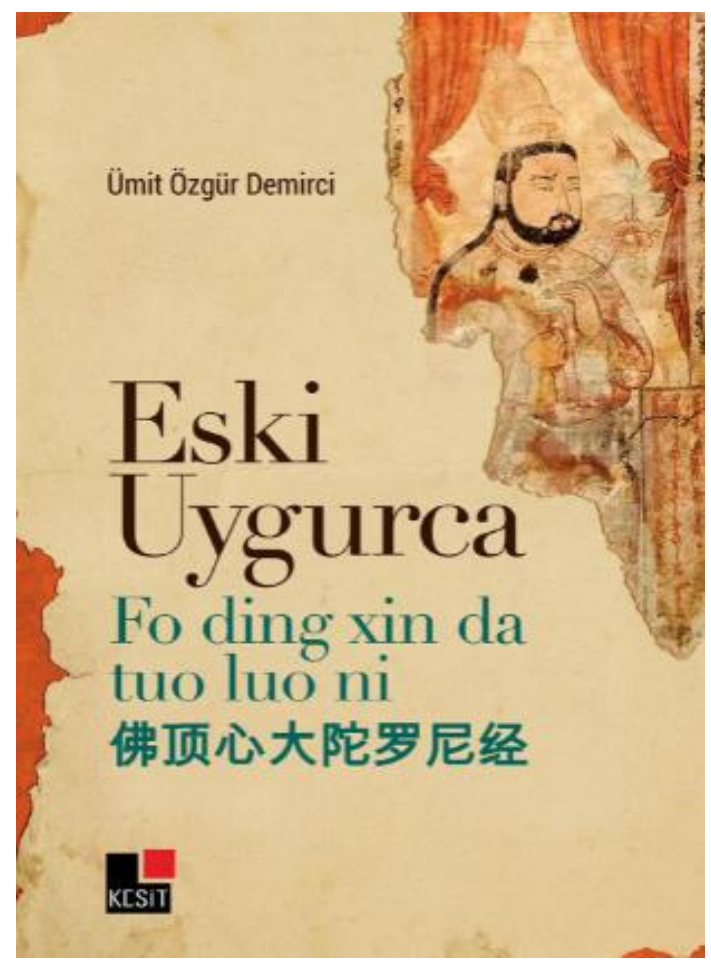
saklanmaktadır.

Eser üzerine yapılan çalışmaların hem Türkçe olmayışı hem de yapılan çalışmaların üzerinden uzun bir sürenin geçmiş olması, yeni ve derli toplu bir çalışma yapma ihtiyacı doğurmuştur. Ümit Özgür Demirci "Fo ding xin da tuo luo ni" adlı eseri hazırlayarak bu ihtiyaca cevap vermiştir.

Eser şu bölümlerden meydana gelmiştir:

İçindekiler (5-6), Ön Söz (7-8), Giriş (9-42), Metin (43-88), Türkiye Türkçesine Aktarım (89100) Açıklamalar (101-126), Dizin (127-200) Çince Metin (201-228), Tıpkıbasımlar (229$300)$. Eser, toplam 300 sayfadan ve yedi ana bölümden oluşmaktadır.

*Doktora Öğrencisi, Düzce Üniversitesi, Sosyal Bilimler Enstitüsü, Eski Türk Dili Anabilim Dall, e-posta: aysunsoyer.as@gmail.com 
Eserin Ön Söz bölümünde sūtradan söz edilmiș ve apokrif sūtra olan Fo ding xin da tuo luo $n i$ adlı eser kısaca tanıtılmıştır. Ardından eserin bölümlerine de değinilmiștir. Son olarak yazar teşekkürlerini sunarak bu bölümü bitirmiştir.

Giriş bölümü 1. Fo ding xin da tuoluo ni, 2. Belgelerin Tanıtımı, 3. Metnin İmlâ Özellikleri, 4. Eski Uygur Alfabesi ve Karşılıkları, 5. Kısaltmalar, 6. Kaynakça başlıklı alt bölümlerden oluşmaktadır. Fo ding xin da tuo luo ni başlığı altında Budizm ve sūtra hakkında bilgilere yer verilmiştir. Burada ayrıca eser hakkında bilgi verilmiş, eserin nüshalarına ve muhafaza edildiği yerlere; eserin diğer dillerdeki nüshalarına ve Eski Uygurcaya tercüme edilen eser üzerine yapılan çalışmalara değinilmiştir. Belgelerin Tanıtımı başlığı altında, belgeler tanıtılarak tablo üzerinde gösterilmiştir. Metnin İmlâ Özellikleri başlığı altında, metinden örneklerle ünlü ve ünsüzlerin yazımı gösterilmiştir. Bu başlıkların ardından Eski Uygur Alfabesi ve Karşılıkları, Kısaltmalar, Kaynakça verilerek giriş bölümü tamamlanmıştır. Kaynakça başlığı altında çalışmada kullanılan 67 kaynak APA sistemi kullanılarak belirtilmiştir.

Eserin ikinci bölümünde Eski Uygur Türkçesine ait metnin transliterasyonu (harf çevrimi) ve transkripsiyonu (yazı çevrimi) verilmiştir. Metin bölümünde eserin daha önce yapılan çalışmalar ile karşılaștırılması, okuma farklılıkları ve blok baskı hataları dipnotlar üzerinden belirtilmiştir.

\section{Örnek bir sayfa:}

U 4665h ( T I $\mu$ ) = VOHD 13/19: 197

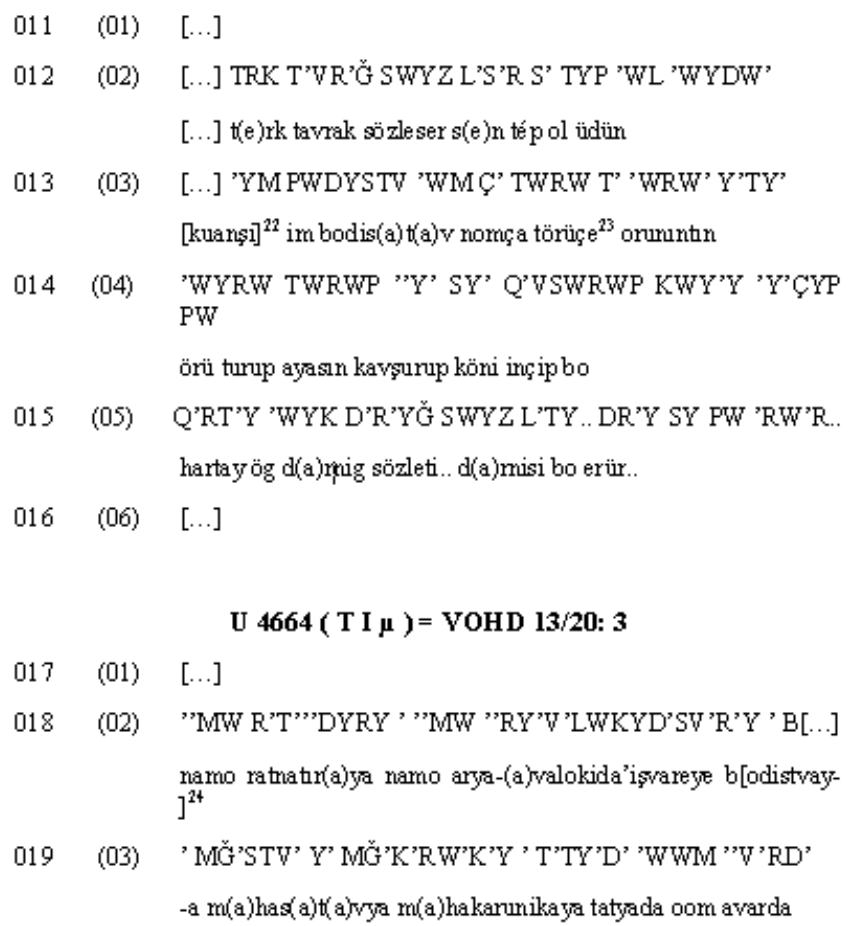

22 Kara-Zieme 1986 325, satr 10 'a göre.

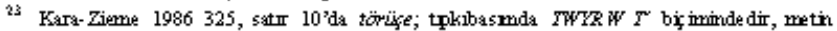
bažlammda nomga tönigse olmas1 gerekir; blok bask hatas var.

24 Kara-Zieme 1986 325, satrI 13 'e göre. 
Eserin üçüncü bölümünde metnin Eski Uygur Türkçesinden Türkiye Türkçesine aktarımı yer almaktadır. Çeviri yapılırken hem anlam hem de cümle bütünlüğünün sağlanması için ait oldukları satır numaraları parantez içinde gösterilmiştir.

Açıklamalar bölümünde Eski Uygurca metin ile Çince metnin karşılaştırılması yapılarak satır numarasına göre sıralanmıștır. Bu karşılaştırmadan hareketle tespit edilen benzerlik ve farklılıklar verilmiştir. Yine bu bölümde metinde yer alan bazı Budist terimlerin anlamları ve metindeki yerleri ele alınmıștır.

\section{Bir örnek:}

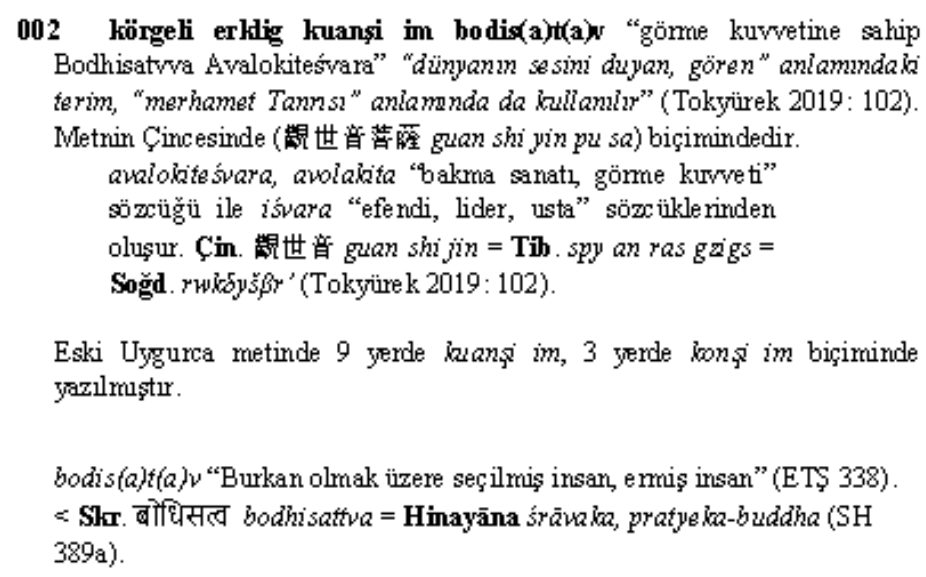

Dizin bölümünde alfabetik sırayla her bir sözcügün Türkiye Türkçesi karşılıklarına, başka dillerden ödünçlenen sözcüklerin tespit edilebilen asli şekillerine, metinde yer alan örneklerine ve bulundukları satır numaralarına yer verilmiştir. Alıntı sözcüklerin hangi dilden alındığı ve o dildeki şekli parantez içinde gösterilmiştir.

\section{Bir örnek:}

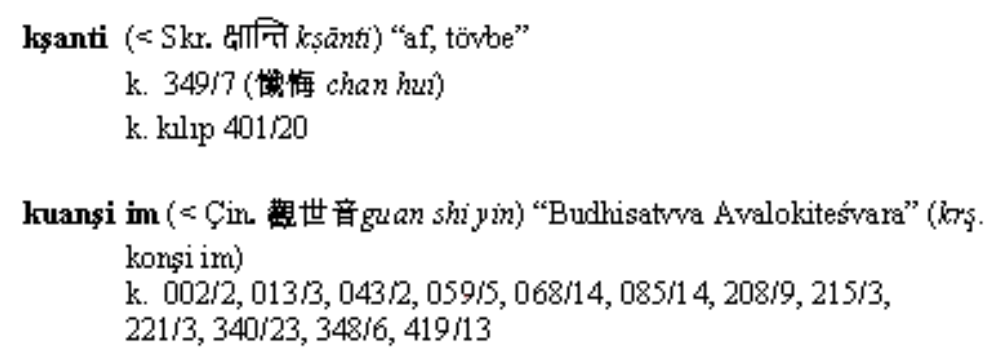

Eserin altıncı bölümü olan Çince Metin 3 farklı bölümde ele alınmış. Her bölümde önce Çince ideogramı ve pinyini, ardından Türkiye Türkçesine tercümesi verilmiştir.

Son bölümde hem Eski Uygur Türkçesine hem de Çinceye ait tıpkıbasımlar yer almaktadır.

Sonuç olarak söz konusu eser, Uygurca çalışmaları için örnek olabilecek nitelikte kullanışlı bir kaynaktır. Eski Uygur Türkçesine ait belgeler hakkında geniş bilginin verilip ardından tablo üzerinde gösterimi okuyucuya kolaylık sağlamaktadır. Tabloda belgelerin eski ve yeni numaraları, A. Yakub'un çalışmasındaki yeri ve metindeki yeri gösterilmiştir. Eski Uygur Türkçesine ait belgelerin tamamının harf çevrimi ve yazı çevrimi verilirken daha önce yapılan çalışmalar göz önünde bulundurularak okuma farklılıklarının ve blok baskı hatalarının dipnotlar üzerinden belirtilmesi okuyucuya karşılaştırma imkânı sunmaktadır. Kitapta yazınsal bilgilerin yanı sıra tıpkıbasımlara ait görsellere de yer verilmiştir. Eski Uygur Türkçesi çalışmalarına ve araştırmalarına kaynaklık edecek bu çalışmayı hazırlayan Ümit Özgür Demirci'ye teşekkür eder, yeni çalışmalarda başarılar dileriz. 


\section{Kaynakça}

DEMİRCI, Ümit Özgür. (2021). Eski Uygurca Fo ding xin da tuo luo ni. İstanbul: Kesit Yayınları. 